\title{
Effect of electron beam irradiation and poly(vinyl pyrrolidone) addition on mechanical properties of polycaprolactone with empty fruit bunch fibre (OPEFB) composite
}

\author{
N. A. Ibrahim ${ }^{1}$, S. N. A. Ahmad', W. M. Z. W. Yunus ${ }^{1}$, K. Z. M. Dahlan ${ }^{2}$ \\ ${ }^{1}$ Chemistry Department, Faculty of Science, Universiti Putra Malaysia, UPM Serdang, 43400 Selangor, Malaysia \\ ${ }^{2}$ Malaysian Nuclear Agency, Bangi 43000 Kajang, Malaysia
}

Received 7 January 2009; accepted in revised form 23 February 2009

\begin{abstract}
Biodegradable composites or green composites were prepared by melt blending technique using polycaprolactone and oil palm empty fruit bunch fibre (OPEFB). Since OPEFB is not compatible with PCL a binder, poly(vinyl pyrrolidone), (PVP) was used to improve the interaction between PCL and OPEFB. The composites produced were irradiated using electron beam to improve the mechanical properties. The tensile, flexural and impact strengths of PCL/OPEFB composites were improved by addition of $1 \%$ by weight of PVP and irradiated with $10 \mathrm{kGy}$ of electron beam. The FTIR spectra indicate a slight increase of frequencies at $\mathrm{C}=\mathrm{O}$ peaks from 1730 to $1732 \mathrm{~cm}^{-1}$ after irradiation indicates some interaction between $\mathrm{C}=\mathrm{O}$ and $\mathrm{O}-\mathrm{H}$. The surface morphology of the facture surface obtained from tensile test shows no fibre pull out indicating good adhesion between the OPEFB and PCL after addition of PVP.
\end{abstract}

Keywords: polymer composites, biodegradable polymers, mechanical properties

\section{Introduction}

In recent years, the research and development of green polymeric materials has attracted more attention due to the concerns related to the environmental pollution by non degradable plastic wastes. Natural fibre reinforced composites using thermoplastic such as polypropylene and polyethylene as a matrix has been widely use in automotive application but the composites are partially biodegradable. Thus the formulation of composites with matrices, which originate from biodegradable raw material such as polycaprolactone should be investigated.

Polycaprolactone (PCL) is an aliphatic polyester, with adequate mechanical properties and good degradability [1-3]. PCL also has excellent biocompatibility, flexibility and has been used as a plasticizer. PCL is degraded by hydrolysis of its ester linkages in physiological conditions (such as in the human body) and has therefore received a great deal of attention for use as an implantable biomaterial. Major difficulties in using this polymer are poor availability, poor process ability, low toughness, high price and low moisture stability $[4,5]$. The $60^{\circ} \mathrm{C}$ melting point is also too low for many applications. Thus reinforcing with natural fibres is one possibility to reduce the cost, to improve stiffness and to enhance thermal stability. In addition the use of natural fibre such as oil palm empty fruit bunch fibre as filler also improves mechanical properties of biodegradable polymers. Oil palm empty fruit bunch fibre (OPEFB) is one of the major solid wastes produced by oil palm indus-

*Corresponding author, e-mail: norazowa@science.upm.edu.my (C) BME-PT 
try. However the primary drawback of using natural fibres for reinforcement is the poor interfacial adhesion between polar-hydrophilic OPEFB and non polar-hydrophobic plastics. The reinforcement of thermoplastic by means of cellulosic fibres significantly improves stiffness and strength while it drastically reduces the composite toughness [8-10]. A number of methods have already existed today for improving the interfacial interaction between lignocellulosics and thermoplastics [10]. Among them: (i) the chemical modification of a lignocellulosic, either by condensation or free radical reaction [11-19] (ii) the use of modified thermoplastic containing a compound capable of interacting with a lignocellulosic [20-23], (iii) the addition of a third component with the ability to interact simultaneously at the interface with the thermoplastic and the lignocellulosic (compatibiliser) [24-27].

Chemical analysis of OPEFB shows that OPEFB consist of $65 \%$ cellulose and $19 \%$ lignin [6]. Oil palm fibre has relatively high strength and stiffness, low density and causes no skin irritations on contact. Many investigations have been made on the potential of natural fibres as reinforcement for composite but these composites use thermoplastics which are non biodegradable polymers as a matrix [7-9]. These composites have found applications in furniture, packaging, building and automobile industries [10].

Poly( $N$-vinyl-2-pyrrolidone) (PVP) is widely used in different aspects, such as additives to cosmetics, coatings and biomedicines due to its excellent biocompatibility and hydrophilicity [28-32]. PVP binds to polar molecules exceptionally well owing to its polarity. Rovira-Bru et al. [30] has used PVP as a zirconia surface modifier. It was reported the maximum adsorption capacity of protein decreased by up to about $76 \%$. On the other hand, a chemical crosslinking method has been used by Kang et al. [33]. PVP was immobilized within chlorinated poly(vinyl chloride) membrane to improve its liquid permeation behaviours [34].

This paper describes the preparation and characterization of new biodegradable composites from oil palm empty fruit bunch fibre and polycaprolactone. The interfacial adhesion between the polymer matrix and the filler was improved by the radiation method via electron-beam irradiation in the presence of poly(vinyl pyrrolidone) as the compatibiliser.

\section{Experimental}

\subsection{Materials}

Polycaprolactone from Solvay Caprolactone was purchased from Colour Pigment (M) Sdn. Bhd. The compatibiliser used in this study, poly(vinylpyrrolidone) (PVP) was from Merck Schuchardt OHG, Germany. Oil palm empty fruit bunch fibre (OPEFB) was obtained from Sabutek (M) Sdn. Bhd., Perak, Malaysia. The OPEFB fibre was washed by soaking in distilled water for 24 hour to remove the excessive wax and other impurities. The fibre was then rinsed with hot water $\left(60^{\circ} \mathrm{C}\right)$ and acetone prior to drying at $60^{\circ} \mathrm{C}$ in an oven. The fibre was ground to particle size of $200 \mu \mathrm{m}$ by using crusher machine.

\subsection{Sample preparation}

The composites OPEFB:PCL were prepared in 40:60 by weight. The compatibiliser (PVP) was added during the mixing which is ranging from 1 to $5 \%$ by weight. PVP was mixed with OPEFB prior the blending as both are hydrophilic.

\subsection{Electron beam irradiation}

Melt blending was carried out at $70^{\circ} \mathrm{C}$ and $50 \mathrm{rpm}$ rotor speed in Haake rheomixer. The blends were then compression moulded under a pressure of 14.7 $\mathrm{MPa}$ at $70^{\circ} \mathrm{C}$ and $6 \mathrm{~mm}$ thick. The sheets were immediately cooled between two plates of a cold press at $25^{\circ} \mathrm{C}$. The moulded sheets were irradiated using an electron beam (EB) machine EPS Model3000 at 5-40 kGy at room temperature with one side irradiation. After irradiation, the samples were reheated until melt and compressed moulded into 1 and $3 \mathrm{~mm}$ thick sheets for mechanical testing. The accelerator energy of the $\mathrm{EB}$ is $2 \mathrm{MeV}$, beam current of $2 \mathrm{~mA}$ at $5 \mathrm{kGy} /$ pass.

\subsection{Tensile properties}

The tensile strength, tensile modulus and elongation at break were measured by using Instron Universal Testing Machine 4301 at $5 \mathrm{~mm} / \mathrm{min}$ of crosshead speed in accordance to ASTMD638 [36]. Seven samples were used for the tensile test and an average of five results was taken as the resultant value. 


\subsection{Flexural properties}

The flexural strength and flexural modulus were measured with Instron Universal Testing Machine 4301 according to ASTM D790 [37]. The size of the samples tested is $127 \times 12.7 \times 3 \mathrm{~mm}$. The crosshead speed is $1.3 \mathrm{~mm} / \mathrm{min}$ and the support span length is $48 \mathrm{~mm}$.

\subsection{Impact properties}

To evidence the effect of the curing time on the toughening properties of the adhesives, the Izod impact test was carried out according to ASTM D256 standard using an impact tester (IZOD Impact Tester) [38]. The sample size is $63.5 \times 12.7 \times$ $3 \mathrm{~mm}$, the notch length is $2.54 \mathrm{~mm}$.

\subsection{Fourier-transform infrared analysis}

The FTIR spectra of the composites samples were recorded on Fourier-transform IR Spectrophotometer (Perkin-Elmer Spectrum BX). Samples were compressed into thin film before scanning from 4000 to $400 \mathrm{~cm}^{-1}$.

\subsection{Scanning electron microscopy}

The morphology of tensile fracture surface of the composites was observed by scanning electron microscope (SEM) at room temperature. A JEOL (model JSM-6300F) SEM with field emission gun and accelerating voltage of $10 \mathrm{kV}$ was used. A gold coating of a few nanometres in thickness was coated on tensile fracture surfaces. The samples were viewed perpendicular to the fractured surface.

\section{Results and discussion}

Composites with good mechanical properties can be obtained when the filler is well dispersed in the matrix. In addition the filler and the matrix should be compatible, thus addition of PVP which acts as the binder to the filler (OPEFB) helped to improve the mechanical properties of the composites. Interaction and adhesion between the OPEFB and PCL can also be improved by irradiation of electron beam which induced crosslinking in the presence of PVP.

\subsection{Effect of radiation dose and PVP on tensile properties}

Radiation processing concerns molecular weight increase by irradiation induced crosslinking and decrease in molecular weight when the radiation tends to promote degradation by chain scission reaction and the process depends on the absorbed dose [39]. Figures 1 and 2 show the effect of absorbed dose on tensile strength and modulus respectively. From this study $10 \mathrm{kGy}$ gives the optimum absorbed dose to produce composites with good mechanical properties.

Figure 3 depicts the comparison of tensile strength between irradiated (10 kGy) and non-irradiated

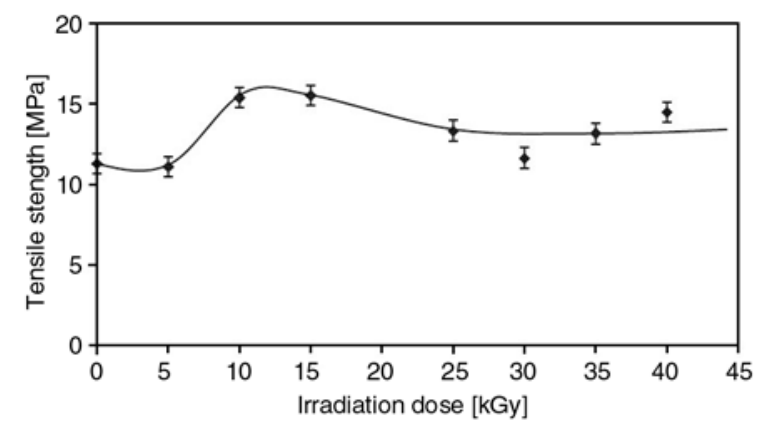

Figure 1. Tensile strength of OPEFB:PCL (40:60) composites with $10 \%$ of PVP content at various irradiation dose

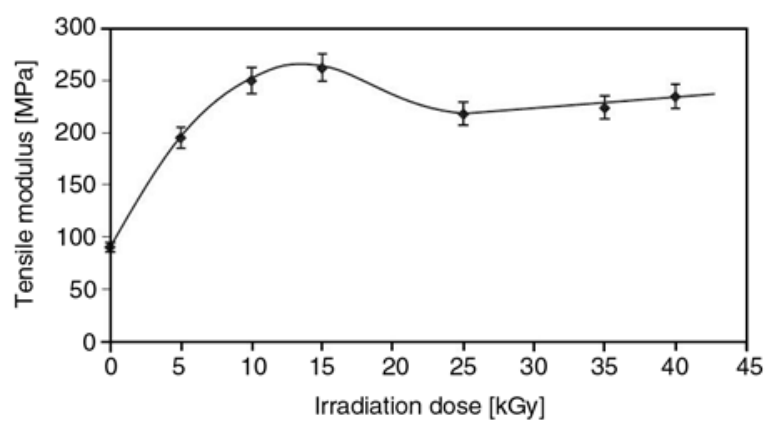

Figure 2. Tensile modulus of OPEFB:PCL (40:60) composites with $10 \%$ of PVP content at various irradiation dose

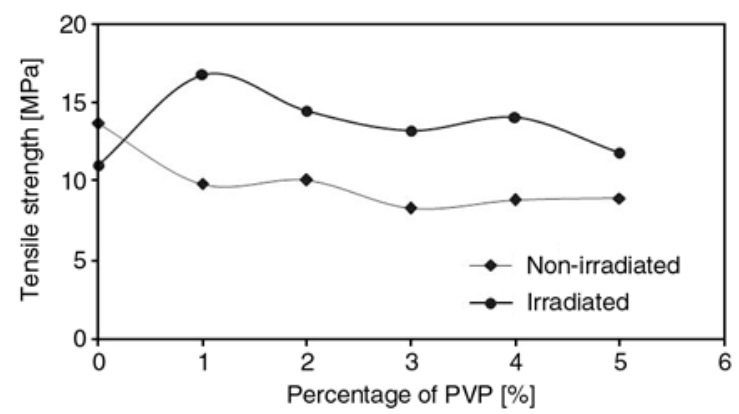

Figure 3. Tensile strength of irradiated and non-irradiated OPEFB:PCL composites at various PVP content 
OPEFB/PCL composites with and without PVP. Tensile strength of composites decreased with the addition of PVP in non-irradiated composites indicating that no improvement in interaction between OPEFB and PCL. Irradiation of the composites with $10 \mathrm{kGy}$ of electron beam improved the tensile strength significantly. The addition of $1 \% \mathrm{PVP}$ in OPEFB/PCL composite has enhanced the crosslink density resulted in an increase in tensile strength [1]. The drops in tensile strength with the increase of PVP may be due to the formation of excessive crosslinking in the composites which results in embrittlement of the samples. Only $1 \%$ of PVP is needed to improve the tensile strength by $71 \%$ after the irradiation.

Figure 4 shows almost similar results with tensile strength where irradiation gives higher modulus. A high tensile modulus means that the material is rigid - more stress is required to produce a given amount of strain which means it resists deformation or stretch. The tensile modulus increased significantly with the addition of $1 \%$ PVP after irradiation as shown in Figure 4. The increase in tensile modulus is due to the inherent the stiffness of the polymer matrix and of the filler, and to the crosslinking that made the polymer more rigid, as revealed by a slight decreased in elongation at break (Figure 5).

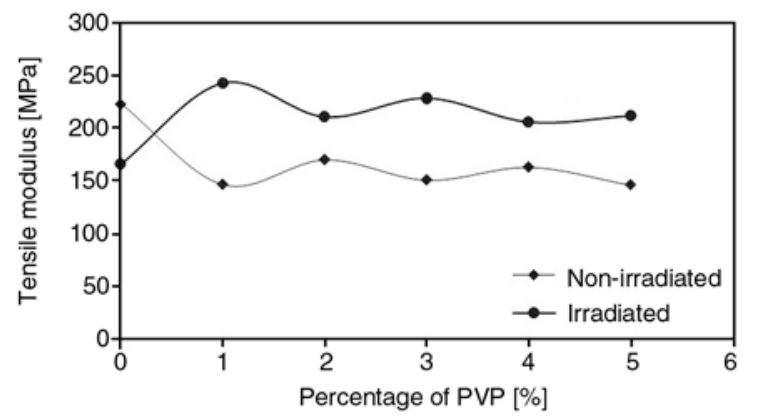

Figure 4. Tensile modulus of irradiated and non-irradiated OPEFB:PCL composites at various PVP content

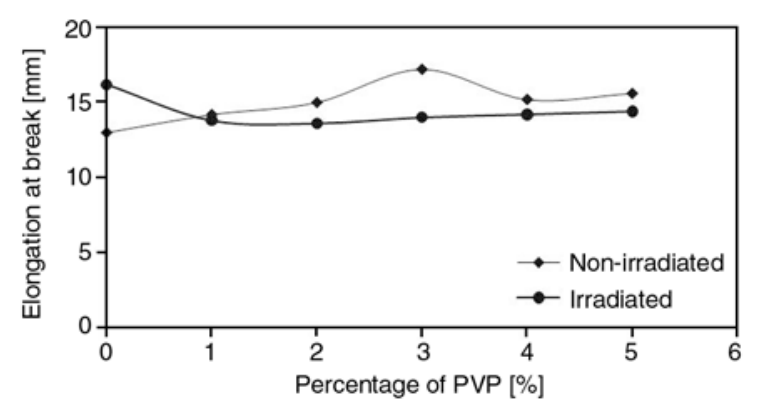

Figure 5. Elongation at break of irradiated and non-irradiated OPEFB:PCL composites at various PVP content
The improvement in interaction between OPEFB and PCL are also indicated by the increase in the stiffness of the composites.

Figure 5 shows that elongation at break for irradiated composites is slightly lower than compound without irradiation. This is due to better stiffness and strength attributed to the strong adhesion between fibre and polymer matrix. Consequently, the toughness of the composites is reduced, resulting in lower elongation at break. Higher toughness is obtained from weak interfacial adhesion as shown by non-irradiated composites. Weak interfacial bonding resulted in energy adsorption mechanism, i.e. bond breakage at the fibre/matrix interface and pull out fibre caused higher toughness in the composites [40].

\subsection{Flexural properties}

Flexural strength of the composites which were subjected to electron-beam irradiation is $15 \%$ higher (Figure 6) than that of the non-irradiated compound at $1 \%$ of PVP. The trends for both compounds are quite constant. Therefore, they remain nearly unaffected by the amount of compatibiliser, PVP. However, the overall results for irradiated samples are slightly higher, caused by the better adhesion between the fibre and matrix which provides an increase in stress transfer from the matrix to the filler, thus increased stress at failure and the higher values for flexural strength [41]. Flexural modulus (Figure 7) shows almost similar trend with flexural strength which means irradiation caused the composites to become stiffer, attributed to mild crosslinking reaction in the composites. Thus, electron beam irradiation results in significant improvement in tensile properties as well as flexural properties of the composites.

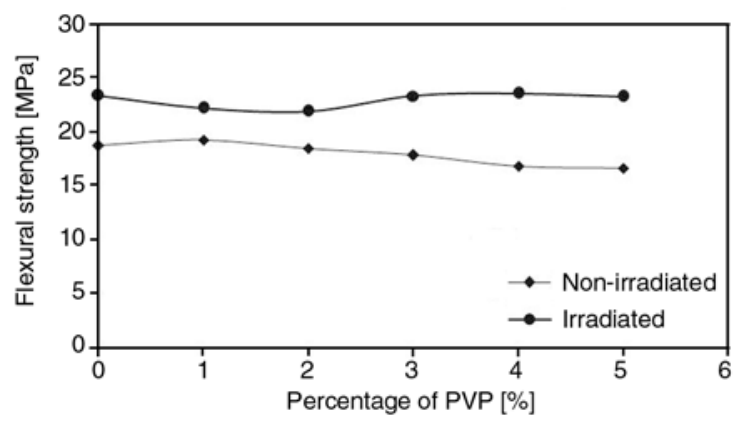

Figure 6. Flexural strength of irradiated and non-irradiated OPEFB:PCL composites at various PVP content 


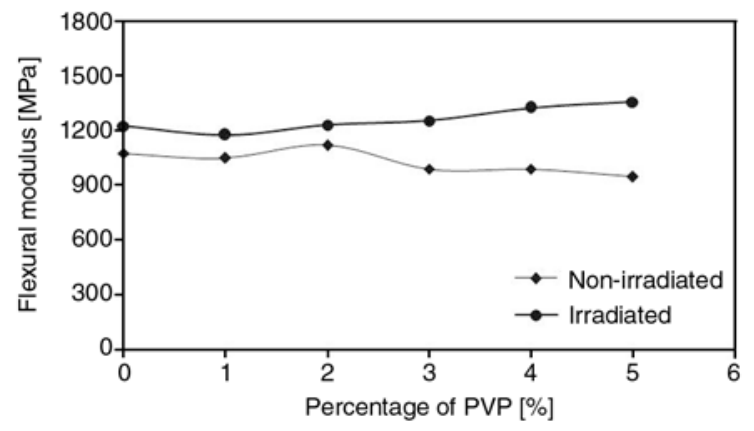

Figure 7. Flexural Modulus of irradiated and non-irradiated OPEFB:PCL composites at various PVP content

\subsection{Impact properties}

It was reported earlier that with increasing filler contents both unnotched and notched impact strength decreased linearly. The presence of woodfibres in the polymer matrix provides points of stress concentrations, thus providing sites for crack initiations. Another reason for decrease in impact strength could be the stiffening of the polymer chains due to bonding between wood-fibres and matrix. For high impact properties, in fact, a slightly weaker adhesion between fibre and polymer is desirable [41]. However, this hypothesis could only be used in the case of low filler content. For the composites with poor interfacial adhesion between fibre and matrix, the toughness of composites will decrease abruptly with increasing of fibre content and remains constant at the particular point. This can be observed in Figures 8 and 9 for both unnotched and notched composites. The impact strength of irradiated composites was higher than those without irradiation. This may be due to the improved interaction between fibre and matrix after the irradiation. For the unnotched composites, the optimum impact strength was achieved at $1 \%$ of

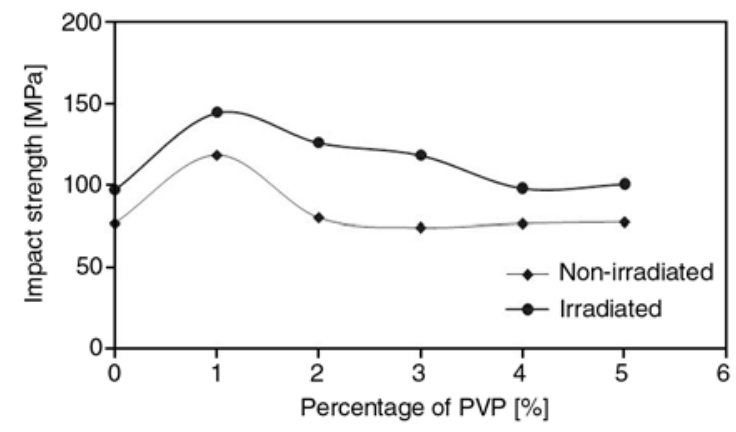

Figure 8. Unnotched impact strength of irradiated and non-irradiated OPEFB:PCL composites at various PVP content

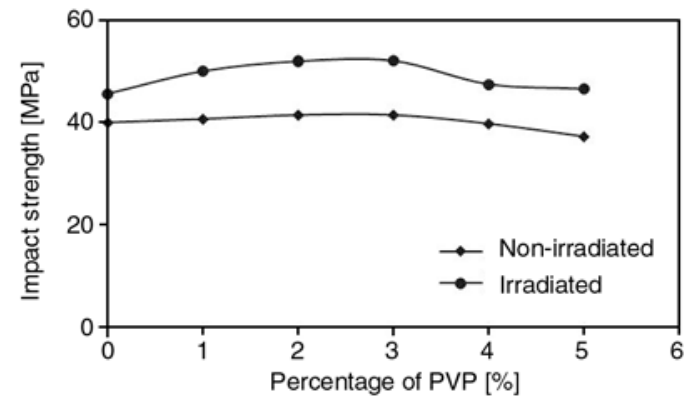

Figure 9. Notched impact strength of irradiated and nonirradiated OPEFB:PCL composites at various PVP content

compatibiliser. As for the notched samples, a slight change was observed which is the impact strength increased with the irradiation.

\subsection{Fourier transform infra red (FTIR) analysis}

FTIR spectroscopy is a technique that is sensitive to specific intermolecular interaction [42]. Kim and Choi [43] observed shifting of peaks in IR spectra when their blends have a strong interaction such as hydrogen bonding. In this study FTIR spectroscopy was used to monitor the absorption peak shifts in specific regions to determine the known functional group interactions of the PCL with OPEFB or PVP. The regions of interest are $1750-1700 \mathrm{~cm}^{-1}$ and $3600-3000 \mathrm{~cm}^{-1}$ for $\mathrm{C}=\mathrm{O}$ and $\mathrm{O}-\mathrm{H}$ stretch respectively. Figure 10 shows the FTIR spectra of irradiated and non-irradiated OPEFB/PCL composites. The $\mathrm{C}=\mathrm{O}$ peaks appear at $1730 \mathrm{~cm}^{-1}$ for both OPEFB:PCL and OPEFB:PCL:PVP $1 \%$ spectra indicating there is no extra interaction or new bond formed with the $\mathrm{C}=\mathrm{O}$ group before irradiation. After irradiation, there is a slight peak shifting appears at $\mathrm{C}=\mathrm{O}$ for the irradiated sample compared

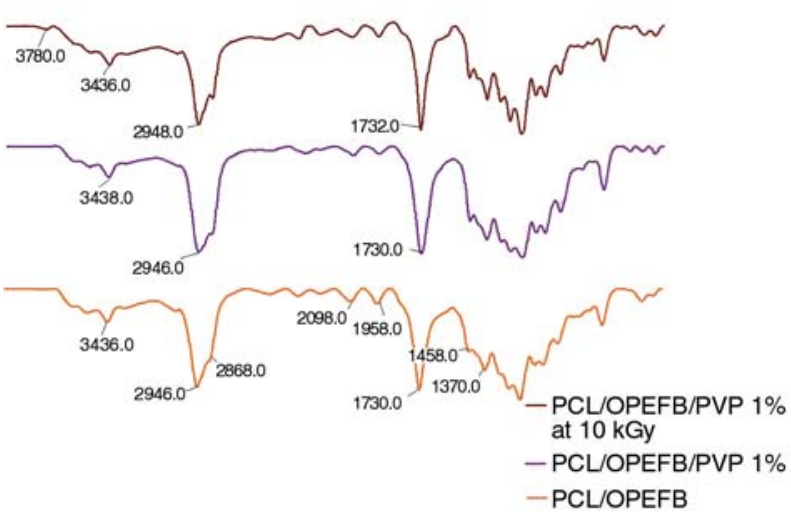

Figure 10. FTIR spectra of OPEFB/PCL composites 
to the samples prior irradiation which is 1732 and $1730 \mathrm{~cm}^{-1}$ respectively, thus indicating some interactions occurs at the carbonyl group.

\subsection{Morphology}

Figures 11a-11c show tensile fracture surfaces for the composites. In the case of without compatibiliser and irradiation, many cavities could be seen where the fibre has been pulled-out (Figure 11a), attributed by poor fibre/matrix adhesion. The holes proximity also indicates that fibre could not provide an efficient stress transfer from the matrix to the filler causing them to have lower mechanical properties in response to stress. Figure $11 \mathrm{~b}$ also indicates the almost similar result with the former, where many cavities are to be seen compared to Figure 11c. From the micrographs, more fibrebreakage could be seen in the composites incorporating PVP and irradiation, causing them to have better fibre matrix adhesion which is in agreement with the mechanical properties reported above. As suggested by Adolfsson et al. [35] PVP binds to polar molecules exceptional well owing to its polarity.

\section{Conclusions}

OPEFB/PCL composites were successfully prepared by melt blending technique. Some prepara-

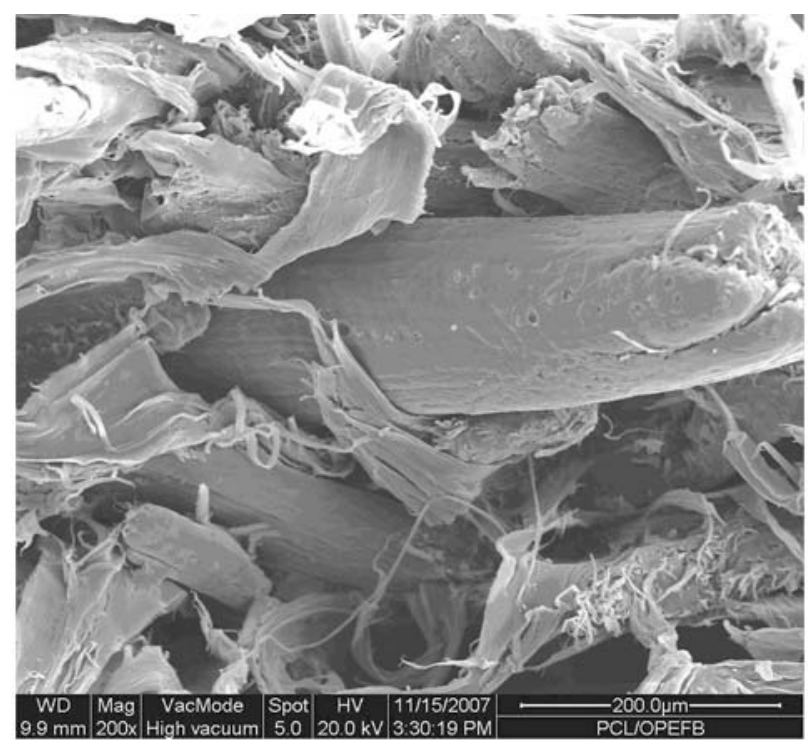

a)

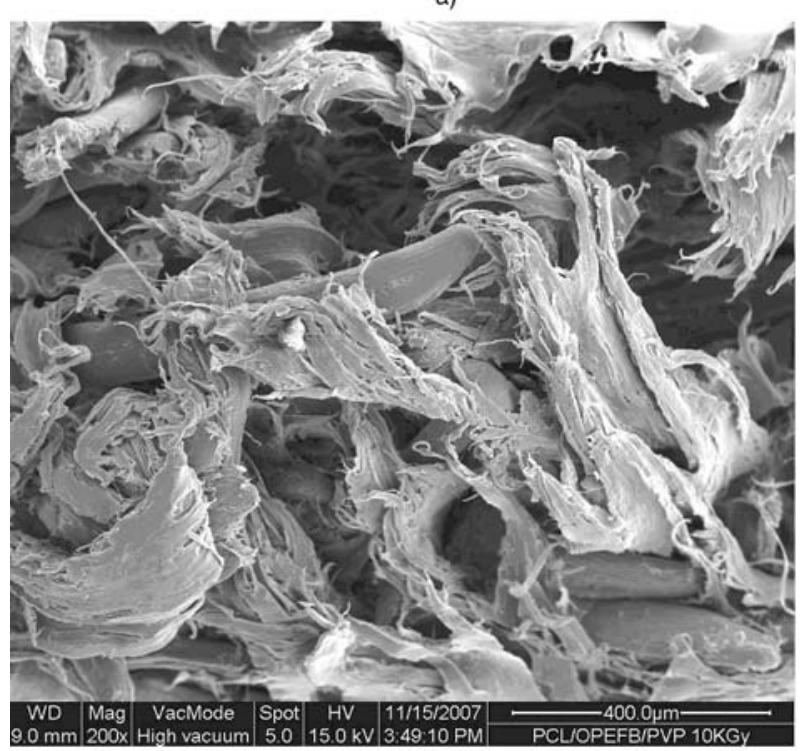

b)

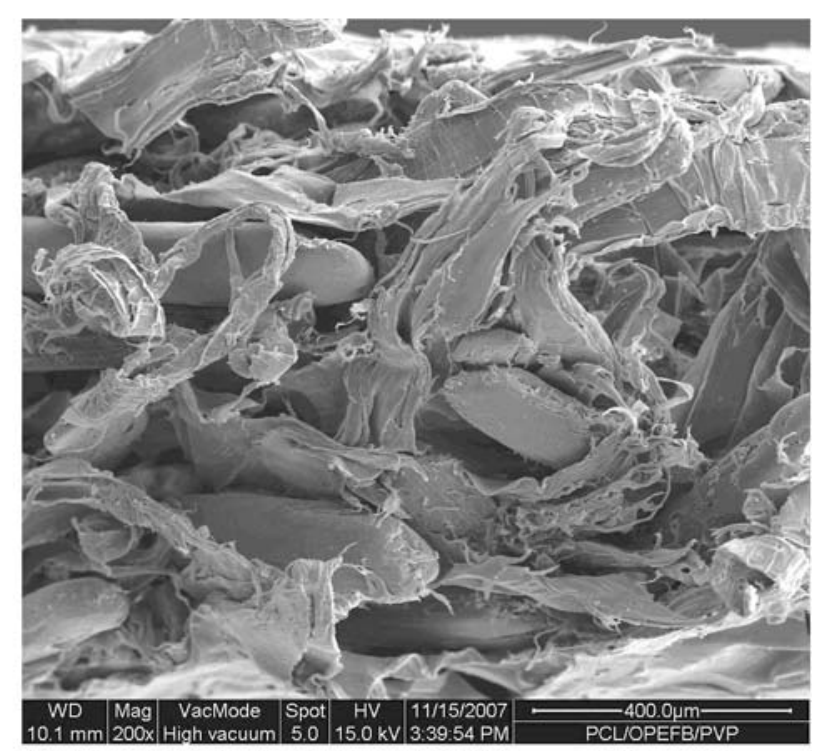

c)

Figure 11. SEM micrographs tensile fracture surface of OPEFB/PCL composites (200x): a) OPEFB/PCL, b) OPEFB/PCL/PVP $1 \%$, c) OPEFB/PCL/PVP $1 \%$ at $10 \mathrm{kGy}$ 
tion conditions such as absorbed dose and amount of PVP were investigated. The mechanical properties of the composites such as tensile, flexural and impact properties have improved significantly with irradiation in occurrence of compatibiliser, indicating a possible crosslinking of the polymer at low dose of $10 \mathrm{kGy}$ and $1 \%$ PVP. The tensile strength of PCL/OPEFB without PVP and treatment is 10.3 MPa whereas after addition of PVP and treatment the tensile strength increased to $16.7 \mathrm{MPa}$ indicating good stress transfer from OPEFB to PCL matrix. PVP acts as binder and cross-linker in the presence of electron beam irradiation provide good adhesion or interaction between OPEFB and PCL. Scanning electron microscopic analysis on the fractured surface of the tensile test also indicates good adhesion between OPEFB and PCL.

\section{Acknowledgements}

The authors would like to thank the Ministry of Science, Technology and Innovation (MOSTI) for the National Science Fellowship Award that has made this research work possible.

\section{References}

[1] Abdel-Rehim H. A., Yoshii F., Kume T.: Modification of polycaprolactone in the presence of polyfunctional monomers by irradiation and its biodegradability. Polymer Degradation and Stability, 85, 689-695 (2004).

DOI: $10.1016 /$ j.polymdegradstab.2004.03.010

[2] Shinoda H., Asou Y., Kashima T., Kato T., Tseng Y., Yagi T.: Amphiphilic biodegradable copolymer, poly(aspartic acid-co-lactide): Acceleration of degradation rate and improvement of thermal stability for poly(lactic acid), poly(butylenes succinate) and poly( $\varepsilon$-caprolactone). Polymer Degradation and Stability, 80, 241-250 (2003). DOI: $10.1016 / \mathrm{S} 0141-3910(02) 00404-4$

[3] Todo M., Park S-D., Takayama T., Arakawa K.: Fracture micromechanisms of bioabsorbable PLLA/PCL polymer blends. Engineering Fracture Mechanics, 74, 1872-1883 (2007). DOI: $10.1016 /$ j.engfracmech.2006.05.021

[4] Chen L., Ni Y., Bian X., Qiu X., Zhuang X., Chen X., Jing X.: A novel approach to grafting polymerization of $\varepsilon$-caprolactone onto starch granules. Carbohydrate Polymer, 60, 103-109 (2005). DOI: $10.1016 /$ j.carbpol.2004.11.028

[5] Wang L., Ma W., Gross R. A., McCarthy S. P.: Reactive compatibilization of biodegradable blends of poly(lactic acid) and poly( $\varepsilon$-caprolactone). Polymer Degradation and Stability, 59, 161-168 (1998). DOI: $10.1016 / \mathrm{S} 0141-3910(97) 00196-1$
[6] Sreekala M. S., Kumaran M. G., Sabu T.: Oil palm fibres: Morphology, chemical composition, surface modification, and mechanical properties. Journal of Applied Polymer Science, 66, 821-835 (1997).

DOI: 10.1002/(SICI)1097-4628(19971031)66:5<821:: AID-APP2>3.0.CO;2-X

[7] Rozman H. D., Saad M. J., Mohd Ishak Z. A.: Flexural and impact properties of oil palm empty fruit bunch (EFB)-polypropylene composites-the effect of maleic anhydride chemical modification of EFB. Polymer Testing, 22, 335-341 (2003). DOI: $\underline{10.1016 / \mathrm{S} 0142-9418(02) 00109-5}$

[8] Kokta B. V., Chen R., Daneault C., Valade J. L.: Use of wood fibres in thermoplastic composites. Polymer Composites, 4, 229-232 (1983).

DOI: $10.1002 / \mathrm{pc} .750040407$

[9] Woodhams R. T., Thomas G., Rodger D. K.: Wood fibres as reinforcing fillers for polyolefins. Polymer Engineering and Science, 24, 1166-1171 (1984). DOI: $10.1002 /$ pen.760241504

[10] Bledzki A. K., Gassan J.: Composites reinforced with cellulose based fibers. Progress in Polymer Science, 24, 221-274 (1999). DOI: $\underline{10.1016 / \mathrm{S} 0079-6700(98) 00018-5}$

[11] Gardea-Hernández G., Ibarra-Gómez R., Flores-Gallardo S. G., Hernández-Escobar C. A., Pérez-Romo P., Zaragoza-Contreras E. A.: Fast wood fibre esterification. I. Reaction with oxalic acid and cetyl alcohol. Carbohydrate Polymers, 71, 1-8 (2008). DOI: $\underline{10.1016 / j . c a r b p o l .2007 .05 .014}$

[12] Bledzki A. K., Mamun A. A., Lucka-Gabor M., Gutowski V. S.: The effects of acetylation on properties of flax fibre and its polypropylene composites. Express Polymer Letters, 2, 413-422 (2008). DOI: $10.3144 /$ expresspolymlett.2008.50

[13] George J., Sreekala M. S., Thomas S.: A review on interface modification and characterization of natural fibre reinforced plastic composites. Polymer Engineering and Science, 41, 1471-1485 (2001). DOI: $10.1002 /$ pen. 10846

[14] Gupta K. C., Sahoo S.: Grafting of acrylonitrile and methyl methacrylate from their binary mixture on cellulose using ceric ions. Journal of Applied Polymer Science, 79, 767-778 (2001).

[15] Nakamura R., Goda K., Noda J., Ohgi J.: High temperature tensile properties and deep drawing of fully green composites. Express Polymer Letters, 3, 19-24 (2009). DOI: $10.3144 /$ expresspolymlett.2009.4

[16] Mohanty A. K., Mubarak A. K., Hinrichsen G.: Surface modification of jute and its influence on performance of biodegradable jute-fabric/biopol composites. Composites Science and Technology, 60, 1115-1124 (2000).

DOI: $\underline{10.1016 / \mathrm{S} 0266-3538(00) 00012-9}$ 
[17] Redondo S. U. A., Radovanovic E., Gonçalves M. C., Yoshida I. V. P.: Eucalyptus kraft pulp fibres as an alternative reinforcement of silicone composites: I. Characterization and chemical modification of eucalyptus fibre with organosilane coupling agent. Journal of Applied Polymer Science, 85, 2573-2579 (2002). DOI: 10.1002/app.10905

[18] Román-Aguirre M., Márquez-Lucero A., ZaragozaContreras E. A.: Elucidating the graft copolymerization of methyl methacrylate onto wood-fibre. Carbohydrate Polymers, 55, 201-210 (2004).

DOI: $10.1016 /$ j.carbpol.2003.09.008

[19] Thiebaud S., Borredon M. E., Baziard G., Senocq F.: Properties of wood esterified by fatty-acid chlorides. Bioresource Technology, 59, 103-107 (1997). DOI: 10.1016/S0960-8524(96)00160-5

[20] Chauhan G. S., Guleria L. K., Misra B. N., Kaur I.: Polymers from renewable resources. II. A study in the radio chemical grafting of poly(styrene-alt-maleic anhydride) onto cellulose extracted from pine needles. Journal of Polymer Science Part A: Polymer Chemistry, 37, 1763-1769 (1999).

DOI: 10.1002/(SICI)1099-0518(19990615)37:12< 1763:: AID-POLA5>3.0.CO;2-S

[21] Fung K. L., Li R. K. Y., Tjong S. C.: Interface modification on the properties of sisal fibre reinforced polypropylene composites. Journal of Applied Polymer Science, 85, 169-176 (2002). DOI: $10.1002 /$ app. 10584

[22] Matías M. C., De la Orden M. U., González Sánchez C., Martínez Urreaga J.: Comparative spectroscopic study of the modification of cellulosic materials with different coupling agents. Journal of Applied Polymer Science, 75, 256-266 (2000).

DOI: $10.1002 /($ SICI $) 1097-4628(20000110) 75: 2<256:$ : AID-APP8>3.0.CO;2-Z

[23] Navarro Cassu S., Felisberti M. A.: In situ compatibilisation of polystyrene and polyurethane blends by using poly(styrene-co-maleic anhydride) as reactive compatibiliser. Journal of Applied Polymer Science, 82, 2514-2524 (2001).

DOI: $10.1002 / a p p .2102$

[24] Feng D., Caulfiel D. F., Sanadi A. R.: Effect of compatibiliser on the structure-property relationships of kenaf-fibre/polypropylenecomposites. Polymer Composites, 22, 506-517 (2001).

DOI: $10.1002 /$ pc. 10555

[25] Martínez Urreaga J., Matías M. C., De la Orden M. U., Lechuga Munguía M. A., González Sánchez C.: Effects of coupling agents on the oxidation and darkening of cellulosic materials used as reinforcements for thermoplastic matrices in composites. Polymer Engineering and Science, 40, 407-417 (2000). DOI: $10.1002 /$ pen. 11174
[26] Oksman K., Lindberg H., Holmgren A.: The nature and location of SEBS-MA compatibiliser in polyethylene-wood flour composites. Journal of Applied Polymer Science, 69, 201-209 (1998).

DOI: 10.1002/(SICI)1097-4628(19980705)69:1<201:: AID-APP23>3.0.CO;2-0

[27] Rana A. K., Mandal A., Mitra B. C., Jacobson R., Rowell R., Baneerjee A. N.: Short jute fibre-reinforced polypropylene composites: Effect of compatibiliser. Journal of Applied Polymer Science, 69, 329 338 (1998).

DOI: $10.1002 /($ SICI) 1097-4628(19980711)69:2<329:: AID-APP14>3.0.CO;2-R

[28] Mosqueda-Jimenez D. B., Narbaitz R. M., Matsuura T., Chowdhury G., Pleizier G., Santerre J. P.: Influence of processing conditions on the properties of ultrafiltration membranes. Journal of Membrane Science, 231, 209-224 (2004).

DOI: 10.1016/j.memsci.2003.11.026

[29] Mosqueda-Jimenez D. B., Narbaitz R. M., Matsuura T.: Impact of membrane surface modification on the treatment of surface water. Journal of Environmental Engineering, 130, 1450-1459 (2004). DOI: 10.1061/(ASCE)0733-9372(2004)130:12(1450)

[30] Rovira-Bru M., Giralt F., Cohen Y.: Protein adsorption onto zirconia modified with terminally grafted polyvinylpyrrolidone. Journal of Colloid and Interface Science, 235, 70-79 (2001).

DOI: $10.1006 /$ jcis. 2000.7355

[31] Torchilin V. P., Levchenko T. S., Whiteman K. R., Yaroslavov A. A., Tsatsakis A. M., Rizos A. K., Michailova E. V., Shtilman M. I.: Amphiphilic poly$N$-vinylpyrrolidones: Synthesis, properties and liposome surface modification. Biomaterials, 22, 30353044 (2001).

DOI: $10.1016 / \mathrm{S} 0142-9612(01) 00050-3$

[32] Higuchi A., Shirano K., Harashima M., Yoon B. O., Hara M., Hattori M., Imamura K.: Chemically modified polysulfone hollow fibres with vinylpyrrolidone having improved blood compatibility. Biomaterials, 23, 2659-2666 (2002).

DOI: $\underline{10.1016 / S 0142-9612(01) 00406-9}$

[33] Kang J. S., Kim K. Y., Lee Y. M.: Preparation of PVP immobilized microporous chlorinated poly(vinyl chloride) membranes on fabric and their hydraulic permeation behaviour. Journal of Membrane Science, 214, 311-321 (2003). DOI: $10.1016 / \mathrm{S} 0376-7388(02) 00597-5$

[34] Yu H-Y., Xu Z-K., Xie Y-J., Liu Z-M., Wang S-Y.: Flux enhancement for polypropylene microporous membrane in a SMBR by the immobilization of poly( $N$-vinyl-2-pyrrolidone) on the membrane surface. Journal of Membrane Science, 279, 148-155 (2006).

DOI: $\underline{10.1016 / j . m e m s c i .2005 .11 .046}$ 
[35] Adolfsson A., Caramella C., Nyström C.: The effect of milling and addition of dry binder on the interparticulate bonding mechanisms in sodium chloride tablets. The International Journal of Pharmaceutics, 160, 187195 (1998).

DOI: 10.1016/S0378-5173(97)00307-4

[36] ASTM D638-03: Standard test method for tensile properties of plastics (2004).

[37] ASTM D790-03: Standard test method for flexural properties of unreinforced and reinforced plastics and electrical insulating materials (2003).

[38] ASTM D256-90b: Standard test method for impact resistance of plastics and electrical insulating materials (2004).

[39] Chmielewski A. G., Haji-Saeid M., Ahmed S.: Progress in radiation processing of polymers. Nuclear Instruments and Methods in Physics Research B: Beam Interactions with Materials and Atoms, 236, 44-54 (2005).

DOI: 10.1016/j.nimb.2005.03.247
[40] Ismail H., Rosnah N., Rozman H. D.: Curing characteristics and mechanical properties of short oil palm fibre reinforced rubber composite. Polymer International, 38, 4059-4064 (1997).

DOI: $10.1016 / \mathrm{S} 0032-3861(96) 00993-7$

[41] Karmarkar A., Chauhan S. S., Modak J. M., Chanda M.: Mechanical properties of wood-fibre reinforced polypropylene composites: Effect of a novel compatibiliser with isocyanate functional group. Composites Part A: Applied Science and Manufacturing, 38, 227 233 (2007). DOI: 10.1016/j.compositesa.2006.05.005

[42] Wong S., Shanks R., Hodzic A.: Interfacial improvements in poly(3-hydroxybutyrate)-flax fibre composites with hydrogen bonding additives. Composites Science and Technology, 64, 1321-1330 (2004). DOI: 10.1016/j.compscitech.2003.10.012

[43] Kim B. K., Choi C. H.: Melt blends of poly(methyl methacrylate) with a phenoxy. Polymer, 37, 807-812 (1996).

DOI: $\underline{10.1016 / 0032-3861(96) 87257-0}$ 